\title{
KULTŪRINIŲ POKYČIŲ POVEIKIS \\ TRANSFORMUOJANT POSTMODERNIOSIOS \\ VISUOMENĖS SUVOKIMĄ: PERĖJIMAS NUO \\ "NORMALUMO" SUVOKIMO PRIE „IŠIMČIŲ \\ DIKTATO“
}

\author{
Andrius Vaitkevičius \\ Klaipèdos universitetas
}

\begin{abstract}
Anotacija
Analizuosime kultūros reiškinị, kaip žmogaus genijaus sukurtą produktą. Klausime, kaip šiandien squveikauja kultūra ir žmogaus gyvenimas, kaip kultūrinè transformacija veikia pati žmogaus modeliavimo suvokimo procesą. Analizuosime, kaip kultūrinis suvokimas to, kas „,normalu“, arba to, kas yra „,vertybe“", keičiamas tuo, kas malo$n u$, naudinga. Kaip sukuriamas naujas normalumo ir vertingumo konceptas. Kuriame visuomenę be ribu, pagrista išimtimis, ar pagarbia ir tolerantiška visuomenę? PAGRINDINIAI ŽODŽIAI: prigimtis, kultūra, identitetas, normalumas, išimtis, politinis korektiškumas, narcisizmas, individualizmas, masiu psichologija, ribos, krize, laisvé, žmogaus orumas, kultūrinis identitetas, tèvas, tèvystè.
\end{abstract}

\begin{abstract}
We will analyse the cultural phenomenon as a product created by human genius. We will ask how works the interaction of culture and human life today and how cultural transformation influences the process of modelling perceptions of man himself. We will analyse how the cultural perception of what is "normal" or what is "value" is replaced by what is pleasant and useful. How a new concept of normality and value is created. We are creating a society on the foundation of exceptions without borders or a respectful and tolerant society?

KEY WORDS: nature, culture, identity, normality, exception, political correctness, narcissism, individualism, mass psychology, boundaries, crisis, freedom, human dignity, cultural identity, father, fatherhood.
\end{abstract}

DOI: http://dx.doi.org/10.15181/mtd.v0i7.2311 


\section{Ivadas}

Šio straipsnio pagrindinė mintis - bandyti pažvelgti ị sociokultūrinius pokyčius vakarietiškosios kultūros lygmeniu. Pokyčius, kurie paveikia pačios žmogiškosios būties suvokimo esmę, jos prigimtį. Ir tai, kaip šios sąveikos pagrindu tarp žmogaus genijaus sukurto produkto - kultūros ir šiandieninès politikos - vyksta dialogas, sprendžiant klausimus, kurie susiję su pačiu žmogiškuoju buvimu.

Analizuosime, kaip kultūra veikia prigimties klausimo pateikimo trajektoriją, ịvesdindama ji i normalumo ar nenormalumo dialektiką, ir kaip mąstant postmodernistinio pasaulio kategorijomis tai tampa kalbejjimu apie išimtis bei jų įnorminimo galimybes, pagrịstas žmogaus orumo užtikrinimo galimybe. Kelsime klausimą, kaip ši naujųjų postmodernistinių laikų visuomenè tampa išimčių visuomene ir kaip gimsta vidinis konfliktas? Ar galima surasti bendrą vardikli, atskaitos tašką, kuris igalintų spręsti kylančius iššūkius, siekiant užtikrinti visų suinteresuotų šalių darnų sugyvenimą ir teises?

Straipsnio objektas - kultūrinių pokyčių poveikis visuomenejje besiformuojančiam normalumo suvokimui ir išimčių fenomenas.

Straipsnio tikslas: išnagrinèti, kaip vyksta visuomeniniai suvokimo pokyčiai, kuo jie pagrịsti ir kaip kinta paties žmogaus suvokimas, paremtas „naujojo normalumo“ samprata, besiremiančia išimčių formavimo logika.

Darbo uždaviniai:

1. Analizuoti sociokultūrinių pokyčių paties žmogaus suvokimo virsmus šiandienèje visuomenèje.

2. Analizuoti, kaip kultūra ir jos pokyčiai veikia politinę ir bet kurią kitą žmogaus veiklos sriț, kreipiant dialogą per „,normalumo“ vertinimo kriterijų.

3. Atskleisti žmogiškosios prigimties klausimą kaip raktinị, siekiant visuotinio sutarimo su žmogaus egzistencija susijusiais klausimais.

Metodai: mokslinès literatūros analizè, interpretacija, sintezè.

\section{Kas yra kultūra?}

Kultūros sąvoka ir konceptas šiandien moksle užima centrinę vietą. Nes analizuoja socialinius reiškinius ir tikrovę, pateikdamas būdą, kaip juos suvokti 
bei interpretuoti. Kultūra šiandieniame kontekste suvokiama kaip esminis dinamizmas, veikiantis visas socialinio, ekonominio, politinio ir tarptautinio gyvenimo formas; ji yra kelrodis, kreipiantis studijų objekto link ir nurodantis, kuria linkme eiti (plg. Carrier, 1997, p. 137). Kultūra yra paskutinis biologinès evoliucijos etapas, kurio link mes stumtelimi tam, kad suvoktume, jog visuomenè laikosi ịprastų ir simbolinių taisyklių, statuso, visuotinių vertybių, vykdo mainus. Tai mus skiria nuo gyvūnų ar gyvenimo, laikantis vien tik biologinių taisyklių.

Galima tvirtinti, kad kultūra yra skiriamasis visuomenès, socialinės grupės ar žmonių bendruomenès ženklas. Būtent dèl to galime kalbèti apie darbuotojų, jaunimo, emigrantų, etninių grupių ir t. t. kultūrą. ,Kultūra yra žmogaus genijaus produktas, suprantamas plačiaja prasme; tai sąmoningai ir nesąmoningai sukurta psichosocialinė matrica, kolektyvizmas: tai yra jos gyvenimo ir visatos aiškinimo pagrindas; jos pačios praeities ir ateities projekto išsipildymas, jos institucijų, tipiškų kūrinių ịpročių, ịsitikinimų, būdingų nuostatų ir elgsenos vaizdavimas, jos originalus būdas bendrauti, gaminti, kurti, keistis gèrybėmis, švęsti ir galimybẻ atskleisti savo sielą bei pačias intymiausias vertybes"(Carrier, 1997, p. 139).

Kultūros sąvoka patyrẻ nemažai pokyčių, ypač per pastaruosius du šimtmečius. Pabandykime suprasti dabartinę šio termino prasmę ir tai, kaip šiuolaikinẻ kultūra ịsiterpia ị kiekvieno žmogaus gyvenimą ir kaip jị keičia, užimdama žmogiškosios prigimties vietą. Žinoma, norint suprasti šiandienos kultūrą ir jos raidą, reikia suprasti pačią kultūros sąvoką - tai yra jos ištakas ir šaknis.

1843 m. publikuotame savo darbe „Bendroji kultūros istorija“ (Allgemeine Culturgeschichte) G. Klemm'as aiškinasi, kaip keičiasi kultūros žodžio reikšmè, turint omenyje laipsnišką žmonijos vystymąsi. Analizuodamas šio autoriaus veikalą S. Belardinelli’s teigia, kad ,čia žodis kultūra jau reiškia ne tik švietimą, ugdymą, tai yra tai, kas išreiškiama vokišku žodžiu Bildung, bet ir kažką daugialypio, susijusio su visa civilizacija, ką galima apibūdinti kaip jos išskirtinius komponentus, taip pat ir jos bendrają raidą“(Belardinelli, 2007, p. 99).

Anglų antropologas E. B. Tylor'as kalba apie kultūrą klasikiniu jos apibrèžimo būdu. Jis rašo: „Sudètinga visuma, apimanti pažinimą, įsitikinimus, meną, moralę, teisę, papročius, kitus jo, kaip visuomenès nario, igytus žmogiškuosius igūdžius“"(Demarchi, Ellena, Cattarinussi, 1987, p. 636). Viename sociologijos 
žodynų rašoma, jog „kultūra, be to, kad teoriniu požiūriu yra prasminga sąvoka, vis dažniau pateikiama kaip empirinių tyrimų objektas, iš naujo apibrèžiantis jos turinị ir funkcijas, atsižvelgiant ị socialinį, organizacinị ir politinị kontekstą, ị kurị įtraukta“" (Demarchi, Ellena, Cattarinussi, 1987, p. 639).

\section{Problematikos aktualizavimas}

Sociologas E. Durkheim'as ėmèsi analizuoti kultūrinị potencialą, iš kurio bendruomenès semiasi integralios galios. Savo dèmesị jis sutelkè ties kultūros reiškinių ir normalumo bei patologiškumo skirtingumo, kuris tampa socialinio ir moralinio normalumo forma, analize (plg. Durkheim, 1969). Tiesą sakant, sociologiniai pokyčiai ne tik verčia mus nuo tapatumo logikos pereiti prie tapatinimosi logikos, bet ir leidžia suvokti tai, kas priklauso prigimtinei logikai, o kas - kultūrinių darinių logikai. R. Spaemann'as rašè: „Prigimtis reiškia tą pagrindinị normalumą, kuris, skirtingai nei nuo kultūros priklausomas normalumas, yra ne tik faktiškai, bet ir pagal teisę ịtraukiamas nagrinèjant šią problematikąa“" (Spaemann, 1994, p. 195).

Šiuolaikinis individualistiškai gyvenantis žmogus vis labiau gyvena paisydamas tik savų norų, vengdamas atsižvelgti ị kitus, jų poreikius ir teisingus norus. Taigi visuomenè, įstatymai, kultūra, tarnaujantys individui, gina pavienių individų ar mažų grupių teises ir norus. Tad iš tiesų gana dažnai atsiduriama opozicijoje, oponuojant visai visuomenei, naikinant ją iš vidaus, kuriant naujas taisykles, ịstatymus, numatant išimtis.

Šiandien reikia turèti omenyje tai, kad žodis kultūra talpina savyje dvejopą reikšmę: vieną - senesnę, klasikinę, humanistinę, nukreiptą į „kultūros žmones“, kitą - modernesnę, antropologinę, vartojamą, siekiant apibūdinti „kolektyvinę psichologiją“ (,masių psichologiją") ir tipišką tam tikros žmonių grupès gyvenimo būdą, kuris šiandienos visuomenèje yra ne kas kita, kaip kompensacinis mechanizmas, veikiantis siekiant užtikrinti prigimtinejje šeimoje patirto santykių deficito kompensavimą. Čia būtų galima daugiau kalbèti apie trejybinio vaiko, motinos, tèvo santykio deficitą, kurio kompensaciniai mechanizmai veikia jau ne tik privačiame gyvenime, bet ir formuojant viešą kultūrinį, įstatyminị, normatyvinị gyvenimą. 


\section{Išimčių koncepto aiškinimas}

Išimčiu koncepcija yra socialinè, ne sociologinè. Tèvo ,išimtis“ suponuoja santykio su tėvu galimybę (čia turime mintyje psichologinį dèsni, kuris tėvą regi kaip ribų nustatytoją šeiminiame santykyje, jis yra supažindintojas su įstatymu, kartu ir išimtis iš to paties įstatymo, tokie Edipo komplekso subtilumai). Tačiau vakarietiškuoju teisiniu pagrindu kuriamose valstybėse santykiai grindžiami laikantis ne autoriteto, bet visuomenès keitimo lygybès principo (lygybès įstatymai, lygios teisès). Visiems galioja tos pačios teisès. Visiems, kalbant psichologine kalba, galioja tas pats „tabu“. Mokslinis universalizmas visus žmones stato ant lygybès principo pakopos. İstatymai, socialinè politika, administracinè teise - visa kuriama taip, kad net subjektas būtų suvokiamas žvelgiant per šią lygybės prizmę: asmens gerovè, santykiai, netgi mintys (biopolitika) ir t. t.

Čia kyla konfliktas kalbant apie paties žmogaus suvokimo esmę. Žmogaus, kuriam tėvo statusas, nesvarbu, kas ji prisiima, užima pamatinę vietą gyvenime. Jau pats tévo vardas lemia santykio su tikrove stabilumą, nes norèdamas sukurti ịstatymą, turi numatyti jo išimtis. Tam ir būtinas tèvo statusas.

\section{Tèvystė sociologijos moksluose}

Sociologijoje tėvystė turejo apsiriboti privataus elgesio ir jausmų sritimi. Tèvo figūra iš tiesų nesulaukè jokio šios disciplinos dèmesio, kol 1936 m. Frankfurto mokykla nepabrěžè socialinio šeimoje susiformavusio autoriteto svarbos visų autoritarinių mechanizmų veikimui. „Vadovaujantis Frankfurto mokyklos apmąstymais ir daugelio kitų mokslininkų įžvalgomis, ypač pradedant 1960 metais, daugiausia dėmesio skirta vidinių šeimos santykių mechanizmų analizei. Taigi tẻvystė palieka „natūralių“ jausmų sritị ir tampa pagrindine socialinès dinamikos dalimi, aplink kurią susitelkia prieštaringos laisvès ir autoriteto kategorijos: iš ,,privačios“ sferos tèvystė patenka ị ,,viešąją““ (Demarchi, Ellena, Cattarinussi, 1987, p. 1839). Taigi tèvo figūra atsiduria tarp individo bei visuomenès ir suvokiama ,kaip šeimos ir socialinio autoritarizmo ịteisinimo struktūra“"(Demarchi, Ellena, Cattarinussi, 1987, p. 1839). 
Sociologija kalba ne tiek apie tėvo ar tėvų statusą, kiek apie jų vaidmenis. Iš tikrujjų ,,vaidmuo atskleidžia dinaminį statuso aspektą. Individas yra socialiai priskirtas statusui, kurị užima kitų statusų atžvilgiu. Naudodamasis teisèmis ir pareigomis, kurios priklauso jo statusui, jis atlieka tam tikrą vaidmenį “ (Demarchi, Ellena, Cattarinussi, 1987, p. 2060). Sociologijoje vaidmenys yra ịvairūs socialiniai statusai, susiję su tam tikromis socialinèmis funkcijomis ar su teisių ir pareigų visuma, kurią visuomenè šioms funkcijoms priskiria (plg. Demarchi, Ellena, Cattarinussi, 1987, p. 2060). Taigi sociologijoje apie tėvystę galime kalbèti tik turèdami omenyje šeimos ryšius ir vaidmenis, kuriuos kiekvienas individas atlieka būdamas santykyje su kitu, t. y. savo šeimos viduje, jos atžvilgiu. O kas, jei socialinejje tikrovejje vykstantys reiškiniai ima keisti vaidmenis ir statusus? Kaip netrukus matysime, tėvo statuso klausimas neatsiejamas nuo socialinio „normalumo“ klausimo.

\section{Normalumo ir išimties konceptų sąveika S. Belardinelli’io mokslinėje analizèje}

Sociologas S. Belardinelli's analizuoja visuomenès pokyčius, nagrinėdamas prigimtinius klausimus šiandieninejje kultūroje ir tyrinèdamas normalumo bei išimties sąveiką. Matome, kaip kultūra, kuri turètų padèti žmogui, jo tapatybès ịsisąmoninimo procesui, tampa didžiausiu priešu, nes klastoja kultūrinị paties žmogaus suvokimo būdą. Ši analizè daugiausia bus grindžiama dviem šio autoriaus knygomis, kurios analizuojant ši svarbų klausimą ypač naudingos: „Normalumas ir išimtis, prigimties sugrị̌zimas ị šiuolaikinę kultūrą“ (Belardinelli, 2002) ir „Bioetika: tarp prigimties ir kultūros“ (Belardinelli, 2007).

S. Belardinelli'io teigimu, kalbèti apie žmogaus prigimtị galima turint mintyje du aspektus. Pirmasis, kai žmogaus prigimtis traktuojama kaip (lot.) natura animalis (gyvūnine prigimtimi), antrasis žmogaus prigimties aspektas - tai kultūra, kurios lygmeniu žmogus ,tikrai gali išmokti būti viršesnis už savo paties prigimtị"“ (Belardinelli, 2002, p. 53). Žmogaus prigimtis, išreiškianti save per laisvę (taigi ir kultūrą), atskleidžia ir tos laisvès ribas, taip pat tikslą bei jos išsipildymo galimybę. ,Mums gerai žinoma diskusija apie žmogaus prigimtí, taigi ir apie prigimties bei kultūros santykị, filosofijai visada buvo problema. Žmo- 
gaus prigimtis galiausiai yra neatlygintina laisvè, kuriai tikrai gali būti nustatytos ribos, bet tikrai ne todèl, kad jos turi būti laikomos žmogaus prigimtimi, bet tiesiog todèl, kad mums tai patinka, yra naudinga, mes sutinkame tai padaryti“ (Belardinelli, 2007, p. 50-51).

Šios ribos leidžia žmogui suprasti savo tikrosios prigimties gilumą, tiesą apie ją. Žmogus, gimdamas kaip žmogus, atsineša ir tam tikrą ribotumą bei veikimo būdus. Tačiau, kai iškyla antroji žmogiškoji prigimtis - socialinè-kultūrinè, suvokiame, kad žmogus gali būti formuojamas atsižvelgiant ị tai, kurioje kultūroje gimè, taikant skirtingus ugdymo metodus. Čia ir glūdi didžiausias pavojus, nes šiandienèje visuomenèje būdas ir siekis suvokti žmogaus prigimties tikrovę dažnai keičiasi, atsiradus įvairių naujų kultūrinių paaiškinimų ir suvokimų, kai žmogus tapo priemone, o ne vertybe, kylančia iš pačios autentiškosios žmogiškosios prigimties. Šiame kontekste kyla pavojus, kad žmogaus orumo, jo prigimties kilnumo klausimai nebekils. Mokslinè ir technologinè raida tampa savotišku tikslu dèl savęs paties, žmogus tokioje technomokslinèje visuomenejje praranda savo vertę, nes biologiniai mokslai „sukuria priešingą sampratą, linkusią mažinti, menkinti visa tai, kas žmogiška, taigi ir intelektą bei laisvę, teikiant svarbą tik biologinèms formulèms“ (Belardinelli, 2007, p. 59). Taigi nebesvarbus ir tam tikro individo statusas. Šeimos lygmeniu jau nebekalbame apie tėvų statusą, greičiau tik apie jų vaidmenis, kurie dažnai keičiasi atsirandant vis naujoms gyvenimo šeimoje formoms. Tèvo ir motinos figūros (ir jų suvokimas) keičiasi. Pirmiausia nebereikalingas tampa tèvas, kuris šeiminiame santykyje yra ịstatymo ir ribų (tam tikro negalimumo), limitų liudytojas.

Politiką stengiamasi pritaikyti visuomenès poreikiams, ieškoma ịstatymų ir administravimo „normalumo“. Pirmiausia keliamas lygybės klausimas, nes visuomeneje, kurioje visi yra laisvi ir nori daryti tai, kas jiems atrodo teisinga, suvokiama, kad visi kylantys politiniai klausimai sprendžiami demokratiškai, laimint daugumai (išleidžiant įstatymą). Ieškoma būdų, kaip atstovauti visų valiai, tiksliau, tam, kas manoma, jog yra tiesa. Pavojus slypi tame, kad gali atsitikti taip, jog niekas nebesugebės orientuotis tiesos lygmeniu. Rodos, viską bandoma pateikti tiesiog ịstatymų / ịstatymo ar naujosios normalumo politikos ir kultūros, kuri vadinama ,politiškai korektiška“, lygmeniu, o paaiškinimai - tik moksliniais motyvais. Mokslas tampa politikos dalimi, 
kuri siekia pertvarkyti visuomenę vadovaudamasi universaliais, moksliniais, techniniais kriterijais, kurie iki tol egzistavo kaip paskiros, nuo politikos nepriklausomos mokslo šakos.

Bandoma pakeisti visuomenę, kur administruojant pasitelkiama politika ir siekiama valdyti visus santykius, net santykị su savimi pačiu. Štai kodèl kilo „normalumo“ klausimas, kuris yra šių laikų beprotybė. Kai klausimai paveikia egzistencinę tikrovę, sprendimui priimti vien balsavimo nebepakanka, nes kalbant apie žmogaus laisvę ir orumą ar savo kultūrinę tapatybę tenka savęs klausti, užduodami klausimai yra teisingi ar ne?

Gana dažnai racionalus pokalbis ir tiesos paieškos sumažinamos iki pasekmių skaičiavimo, kai kiekvienas gali pasirinkti savą tiesą. Taigi krypstame akcentuoto reliatyvizmo, kur rizikuojame pasiklysti beieškodami savosios tapatybės, link. Atrasti savo tapatybę įmanoma „tik su sąlyga, kad politika, kaip ir technologijos, ekonomika ir visos kitos socialinès sistemos, iš naujo atras savo ribas, savajji „,nesavarankiškumą“, tai yra susidurs su negalimumu, glūdinčiu pačių dalykų prigimtyje, kurị reikia pagrịstai ištirti, kad būtų įtikinamas ir vertas apsaugoti“" (Belardinelli, 2002, p. 10).

Šiandieninè kultūra žengẻ keletą žingsnių, kurie sociologiniu požiūriu lėmè „normalumo“ krizę. Išimtys teisèkūros požiūriu ir ne tik dažnai prieštarauja prigimčiai, tad sprendžiant sociokultūrinę problemą reikètu grižti prie prigimtinių šaknų, kurios yra teisinio normalumo ir socialinio gyvenimo pagrindas. Kultūra, per kurią asmenys renkasi ir vadovauja savo elgesiui, sutampa su simboliniu, normatyviniu ir instrumentiniu žmogiškojo veikimo mechanizmu. Individas, kurdamas individualizuotas, kultūrines, kalbines prasmès versijas, suteikia naujo suvokimo galimybę. Tad žmogus, pažindamas pasaulį, kultūrinę aplinką, žmones, istoriją, gali priarteti prie tiesos apie save patį, tos tiesos apie save, kurios pats neturi, bet visą gyvenimą nerimastingai ieško (plg. Mitscherlich, 1970, p. 21-23). Gyvenantị melaginga kultūrine tiesa apie save žmogų ištinka tapatybès krizè. Šiuo metu turime savęs klausti, kas nutiktų, jei šia tiesa nuolat būtų kultūriškai manipuliuojama ir ji būtų vis keičiama.

Normalumas ir išimtis pirmiausia atsiskleidžia šeimoje, iškylant naujoms gyvenimo šeimoje formoms ir naujiems patị žmogų aiškinantiems būdams. Šiandienejje tikroveje daugelis žmonių, kalbėdami apie tai, kas yra „norma- 
lu“ ar kas yra „išimtis“, vadovaujasi klaidingu kriterijumi, nes visų pripažinta ir palaikoma tiesa neegzistuoja. Taigi „spazmuojančios „savos egzistencijos“ paieškos yra vis labiau individualizuotos, linkusios i , ,išimtị“, o ne ị ,normalumą“, svajojant apie spontanišką ,savirealizaciją“ be apribojimų, suvaidino dinamiškai nestabilų, prieš šeiminius santykius, ypač tẻvystę, nukreiptą vaidmenį. Didejjantis šeimų susiskaidymas, šeimos formų pliuralizmas, viešųjų institucijų neatsižvelgimas ị socialinị šeimos subjektyvumą, meilès idẻjos, kuri tampa vis narcistiškesnè, nepastovesnè, labiau neapibrěžta, patvirtinimas, jos, susijusios su geidulių tenkinimu, o ne savęs realizavimo kitame ir su kitu idèja, yra tik keletas krizès požymių“ (Belardinelli, 2007, p. 80-81).

Tačiau visuomenė nori išlikti laisva ir demokratiška, o tai jai trukdo, nes kyla daugiakultūriškumo problema, trukdanti atskleisti tiesą apie žmogaus prigimti. Politika turi išspręsti normalumo suvokimo klausimą, nes, kaip matème iki šiol, siekdami išlaikyti liberalų statusą, stengèmès nustatyti tai, kas yra normalu, visada įterpdami ,išimčių“, kurios kartais viršija išimties statusą ir tampa normalumu, pagal kurị privalu, normalu gyventi. Net jei šis normalumas neatitinka prigimties. Šiandieneje Vakarų kultūroje esame šio proceso, kur įstatymus riboja išimtys, rengiami universalūs ịstatymai, galiojantys ne tik Vakarų visuomenejje, bet ir viso pasaulio kontekste, tai yra visai žmonijai, liudininkai.

Tad socialinių santykių lygmeniu „tai, ką priima ir kuo dalijasi daugelis visuomenès narių, yra normalu“ (Belardinelli, 2002, p. 17). Tačiau sparčiai kintančioje visuomenejje tai, kas galioja kaip norma, nesuteikia teisès ją taikyti, nes ieškoma galimybès jos nesilaikyti. „Didèjantis atotrūkis tarp individo ir visuomenès, tarp socialinès ir psichinès sistemos daugiau nei laisvès jausmas lemia sutrikimą, negebejjimą puoselèti santykių su savimi, kitais ir pasauliu“ (Belardinelli, 2002, p. 26). Štai kodèl matome siekị bègti nuo realybès, nuolatinius bandymus patologiniais būdais spręsti vidinius konfliktus, kurie yra gydymo, krizès ịveikimo galimybių paieškos požymiai.

Šiandienè visuomenė gyvena taip, tarsi kiekvienas jos narys turètų teisę i savo „skirtingumą“. Tai lemia narcistiškų asmenybių vystymąsi. Kadangi įstatymai, gindami visų visuomenès narių lygybę, tai leidžia, visuomenė tampa vis anonimiškesnè, individualistiškesnè, nes orientuojasi ị išimtis, asmeninių norų paisymo galimybes. Taigi normalumas, apie kurị kalbame, tampa 
šiandienos kultūros suformuotu normalumu, kuris nebeatitinka prigimtinio žmogaus normalumo. Prigimties ideja nyksta, ji vis svetimesnè, o žmonės tampa savo malonumų vergais: „Paskutinis dalykas, kuriuo turime tikèti, yra tai, kad galime gyventi padoriai, tai yra „žmoniškai“ pasaulyje, kuriame visi yra patys sau išimtis“ (Belardinelli, 2002, p. 35).

S. Belardinelli'io teigimu, ,žmogiškoji būtis suteikia komunikacijos galimybę, kur koegzistuoja ịvairios socialinès sistemos, kurias apibūdina tik jų funkcinis kodas, būdas pasirinkti iš aplinkos gaunamą informaciją ir taip formuoti save kaip tam tikrą išskirtinę sistemą" (Belardinelli, 2002, p. 49). Žmogus priklauso konkrečiai kultūrinei aplinkai, jị formuoja tam tikri kultūriniai požiūriai, aspektai, bet nè vienam iš jų jis nepriklauso: „Būdamas žmogus jis savo ruožtu yra „,sistema“, ,psichine sistema“, veikianti ir uždara, kaip ir visos kitos sistemos, kuriu ,aplinkai“ atstovauja visuomene““ (Belardinelli, 2002, p. 50).

Žmogus turi atkurti prigimties ir kultūros skirtingumą, kad šie du poliai darniai sąveikautų. Nes būtent jis, žinodamas savo unikalumą, gali suprasti ir prisiimti tai, kas priklauso jo paties egzistencijai, kaip užduotị, kurią reikia atlikti. Tikroji problema slypi būtent čia: jei žmogus iš prigimties yra kažkas, tai reiškia, kad jis visada tuo kažkuo buvo ir jo prigimtis nesikeičia. Ši tiesa apie žmogaus prigimtị prieštarauja lygybès ịstatymams, visų pirma galimybei gyventi atsižvelgiant tik ị savo norus, asmeninius poreikius ir ịsitikinimus, kur visi laikomi broliais bei seserimis ir stengiasi gyventi nepripažindami tèvo ar jo statuso.

Nebesant bendros socialiai pripažintos tikrovès, lieka tik susivienodinimo normalumas. Draudžiama drausti, riboti, nes visi lygūs. Nors pavienis individas nepaklūsta bendrajai teisei, jam svarbu būti „normaliu“. Stebime žmonių, norinčių būti legitimiai normaliais, kas yra išimtis, atskyrimą. Taip atsitinka viską suniveliavus iki normalumo lygmens. Paradoksas, kad kalbame apie brolybę ir lygybę, bet tai yra buvimas vaiku (brolija) neturint tėvo. Norint kalbèti apie žmogaus prigimtị, būtina apsibrèžti tai, kas jai nepriklauso, nustatyti ribas. S. Belardinelli'io teigimu, ,viena vertus, iš tikrujų atrodo, kad nebèra jokio „normalumo“, jokių ribų, kita vertus, galime konstatuoti, jog matome galios, kurios vienintelis „matas“, rodos, yra tik ji pati ir savitas 
automatizmas, augimą. Abstrakčiai vienas nuo kito atskirti prigimtis ir protas praranda savo normatyvini pobūdị, tampa bejègiai bei abejingi bet kokios „išimties“ akivaizdoje ir rizikuoja tapti tiesiog „socialinių sistemų“ aplinka, veikiančia nediskriminuojant (be ribų) už pačių žmonių nugaros ir ant jų galvų“" (Belardinelli, 2002, p. 61).

Kad visuomenė tinkamai funkcionuotų, būtinos ,ribos“, kurių nustatyti neįmanoma, nepaisant prigimties - žmogaus prigimties, nes rizikuojama pačiu žmogumi, esančiu santykyje, protauti gebančia laisva būtimi. Moralinès (dorovinès) ribos, nustatytos žmogaus - jo prigimties, deja, dažnai sumenki-

namos iki „kultūros“ dalykų ar pavienio individo asmeninių pasirinkimų. Čia kyla vidinis individo konfliktas, kai jis nebežino, kaip atsakyti, kas teisinga, o kas ne. Jis nebesuvokia, su kuo turètų tapatintis ir kaip surasti savo tapatybę, kuri kasdien surandama, ugdoma iš naujo.

\section{Išvados}

Du ankstesni šimtmečiai pateikè daug skirtingų dalykų, pradedant šeimos, žmogaus orumo ir daugeliu kitų krizių. Šeimos ir žmogaus gyvenimo tikrove šiandien ypač puolama, nestabilioje visuomenèje gyvenantis žmogus jaučiasi klaidinamas, nesaugus, nebegalintis identifikuoti pats savęs: „Jis tampa vis labiau neapibrezžtas, toks neapibrěžtas, kad šiandien nei poezija, nei politika, nei filosofija nebegali to numatyti. Nebegalime pasikliauti nei ,žodžiu“, nei „kalba“, nei ,jausmu“, kurie išliktų stabilūs. Galime būti tikri tik dèl to, kad nesame tikri, ar kažkas, ką prisimename kaip praeiti, ateityje išliks toks, koks buvo“" (Belardinelli, 2002, p. 130).

Taigi žmogus išgyvena krizę, jo „,normalumą“" sudrebinus kažkuo „išskirtiniu“. Kad šią krizę įveiktų, jam būtinas stabilus atskaitos taškas, kuris būtų tẻvo statuso liudijimas ir suteiktų stabilumo tiek pavienio individo, tiek ir visos visuomenès narių pasirinkimams. Taškas, kuris, deja, nesiūlomas, nenurodomas socialinès ir kultūrinès aplinkos, kurioje jis gyvena. Prigimties klausimo sugrąžinimas ị socialini gyvenimą lemtų ir tẻvo statuso grị̌̌imą ị šeiminị gyvenimą, simboliškai - ir ị pačios visuomenès santykị, pagristą prigimtine psichodinamika, aktualijų centru. Nes tẻvystė yra žmogaus prigimtinė esmè. 
S. Belardinelli'o teigimu, būtina sistema, galinti ginti žmogaus orumą sudètingoje realybejje, kur apstu ịvairialypių santykių, kuriuos puoselejjant šis orumas realizuojamas (šeimoje, visuomeneje, su savimi pačiu ir panašiai). Tinkamas žmogaus vystymasis ateityje priklausys nuo to, ar neužmiršime, kad „nepažeidžiant teisèto pliuralizmo, kuriuo galima išreikšti visus žmonių santykius, iš tikrujų egzistuoja ribos (vèlgi „normalumas“), be kurių, puikiai tai žinome ir tai veikia kasdienybejje - kartais labiau nei norime tuo tikèti, santykis prarastų savo ,žmogiškumo“ pobūdị. Šiandienės visuomenès sudètingumas ir rizikos - politinès, ekonominès, ekologinès ir taip toliau - turi būti pasitinkamos naudojantis šiuo kompasu, kuris vienintelis gali realiai tapti sisteminių institucijų ir žmogaus poreikių, „nekokybiško“ ir „žmogiško“ vystymosi tarpininku“ (Belardinelli, 2002, p. 143-144).

\section{Literatūra}

Belardinelli, S. (2002). La normalità e l'eccezione, Il ritorno della natura nella cultura contemporanea. Soveria Mannelli: Rubbettino.

Belardinelli, S. (2007). Bioetica tra natura e cultura. Siena: Cantagalli.

Carrier, H. (1997). Dizionario della cultura, per l'analisi culturale e l'inculturazione. Vertimas ị italų kalbą: M. Tiraboschi. Città del Vaticano: Libreria Editrice Vaticana.

Demarchi, F., Ellena, A., Cattarinussi, B. (eds.) (1987). Nuovo Dizionario di Sociologia. Cinisello Balsamo: San Paolo.

Durkheim, E. (1969) Le regole del metodo sociologico. Milano: Edizioni Comunità. Mitscherlich, A. (1970). Verso una società senza padre. Vertimas ị italų kalbą: S. Bueno. Milano: Feltrinelli.

Spaemann, R. (1994). Per la critica dell'utopia politica. Milano: Angeli. 


\section{THE INFLUENCE OF CULTURAL CHANGES ON THE TRANSFORMATION OF PERCEPTION OF POSTMODERN SOCIETY: THE TRANSITION OF PERCEPTION OF "NORMALITY" TO THE DICTATE OF "EXCEPTION"}

\section{Andrius Vaitkevičius}

Summary

The guiding idea of this article is to try to look at the socio-cultural changes taking place at the level of Western culture. Changes concerning the essence of the perception of the human being itself, of its nature. How is generated the dialogue and the interaction between the product created by human genius - the "culture" and today's politics, and how the issues related to human existence itself are interpreted.

We analyze how the culture influences the trajectory of asking questions about the nature itself, introducing it into the dialectic of normality - abnormality. How, when thinking in the categories of the postmodern world, it turns into talking about exceptions and the possibilities of their normalization. Possibilities for the normalization based on the possibility of ensuring human dignity. The question is, how does this society of the new postmodern world becomes a society of exceptions and how the internal conflict is born? Is it possible to find a common denominator, a starting point, which would enable the arising challenges by ensuring the harmonious coexistence and rights of all the stakeholders?

The past two centuries have forced us to see many different things: starting with the family crisis, human dignity, and many more crises. The reality of family and human life is being brutally attacked, and a person living in a liquid and unstable society feels disoriented, insecure, and no longer able to identify himself: "he becomes increasingly vague, so vague that neither poetry, nor politics, nor philosophy can anticipate it today. We can no longer rely on "word", "language" or "feeling" that would remain stable. We can only be sure about the fact that we are not sure about something we remember as it was in the past it will remain as it was in the future" (Belardinelli, 2002, p. 130). 
Therefore, a person enters a crisis when his "normality" is shaken by something "exceptional", and in order to overcome that crisis, he must have a stable starting point. A point that would be a testimony of fathers function and would provide the stability for choices made by both: the individual and the society. A point which, unfortunately, is not proposed neither presented, indicated by the social and cultural environment in which he lives. The return of the question of nature in the social sphere would make it so that the father, with his function, would return to family life and, in a symbolic sense, to the center of actuality of the relationships of society itself, based on natural psychodynamics. Because fatherhood belongs to the natural essence of human being.

As S. Belardinelli says, there is a need to find a system that can defend human dignity in a complex reality with many multilayer relationships in which this dignity is realizable (family, society, yourself etc.). Proper human development in the future will depend on us. If we will not forget that we must defend the multicultural pluralism in which the human being expresses himself, but at the same time acknowledging the need of the limits (the question of normality). The limits used to describe the character of human being itself.

So, acknowledging the complexity and risks of today's society - at the level of politics economics and so on - we must have a stable starting point, belonging to human being itself. His nature. The question about the nature is the only one who can really mediate between systemic institutions and human needs and development. 